ORIGINAL ARTICLE

\title{
KLOBUCHAR AND NEQUICK G IONOSPHERIC MODELS COMPARISON FOR MULTI-GNSS SINGLE-FREQUENCY CODE POINT POSITIONING IN THE BRAZILIAN REGION
}

\author{
Paulo de Tarso Setti Júnior ${ }^{1}$ - ORCID: 0000-0001-5080-1832 \\ Daniele Barroca Marra Alves² - ORCID: 0000-0002-9033-8499 \\ Crislaine Menezes da Silva ${ }^{1}$ - ORCID: 0000-0003-2023-4237
}

${ }^{1}$ Universidade Estadual Paulista - UNESP, Faculdade de Ciências e Tecnologia, Programa de PósGraduação em Ciências Cartográficas, Presidente Prudente, São Paulo, Brasil.

E-mail: p.setti@unesp.br; crislaine.menezes@unesp.br

${ }^{2}$ Universidade Estadual Paulista - UNESP, Faculdade de Ciências e Tecnologia, Departamento de Cartografia, Presidente Prudente, São Paulo, Brasil.

E-mail: daniele.barroca@unesp.br

Received in $18^{\text {th }}$ June 2018

Accepted in $08^{\text {th }}$ May 2019

\begin{abstract}
:
One of the main error sources in GNSS positioning comes from the ionosphere, an atmospheric layer that stays in the signal path between the satellite and the receiver. For single frequency positioning, the ionospheric effects can be minimized by using an ionospheric model e.g. Klobuchar or NeQuick G. These models are respectively associated to GPS and Galileo systems through their navigation messages, which broadcast coefficients that describe the worldwide ionospheric behavior, and the calculated ionospheric delay is then applied in the pseudorange observations. In this paper, it is presented a comparison between these two models in multi-GNSS (GPS and Galileo) single frequency point positioning, considering two Brazilian stations at different magnetic latitudes, and covered months of weak and strong ionospheric activity from 2013 to 2018. The results indicate a better performance of NeQuick $\mathrm{G}$ model compared to the Klobuchar. Considering all the analyzed periods and stations, Klobuchar improves the positioning accuracy in $16 \%$ and $50 \%$ in periods of weak and strong ionospheric activity, respectively, while NeQuick G improves the accuracy in 31\% and 55\%.
\end{abstract}

Keywords: NeQuick; Klobuchar; Galileo; Point Positioning 


\section{Introduction}

Global Navigation Satellite System (GNSS) based positioning has been increasingly used for a wide range of purposes. It was initiated in the seventies, when the first GPS (Global Positioning System) satellites were launched by the United States Department of Defense (US DoD) (HoffmannWellenhof, Lichtenegger and Wasle 2008). With full operational constellation since 1995 (Seeber, 2003), GPS now has 31 operational satellites (GPS 2018). Galileo is a new GNSS initiated in the nineties, developed and maintained by the European Union for civil purposes. With 22 satellites already in orbit (GSA 2018), Galileo full operational capability will be reached by 2020 (GSA 2016).

Regarding satellite positioning, the ionosphere is one of the main error sources in signal propagation. The range of the ionospheric error is proportional to the Total Electron Content (TEC) along the signal path, which varies depending on observation latitude, local time, season, geomagnetic activity, solar cycle, and other anomalies and irregularities (Seeber 2003). Different methods can be adopted to minimize the ionospheric effect in positioning, such as the use of dualfrequency technique, augmentation system, global/regional TEC map, or an ionospheric model.

Models using ionospheric parameters broadcasted within navigation messages have been widely used to minimize the ionospheric effect on signal propagation for users of single frequency receivers. Klobuchar (1987) developed the first algorithm for ionospheric correction in the mid1970s for GPS single frequency users. NeQuick is a tridimensional and time-dependent ionospheric electron density model. It has been adapted for Galileo single-frequency ionospheric corrections (NeQuick G) to derive real-time predictions based on a single input parameter, the Effective Ionization Level, which can be derived from three parameters broadcasted by Galileo satellites, and the modified dip latitude at the location of the user receiver.

Since Galileo's version of NeQuick was made available, some researches comparing NeQuick G to GPS's Klobuchar model have been presented in literature. Angrisano et al. (2013) simulated the NeQuick G parameters for 3 days of May 2012 and three stations at different magnetic locations in the world, and compared the results to Klobuchar in position domain, obtaining comparable performance in position domain. Piriz et al. (2016) compared both models in range domain (ionospheric delay level), using actual data for the first three months of 2016. For the low-latitude station analyzed, NeQuick G was marginally better than Klobuchar. Wang et al. (2017) also compared both models in range domain for the year of 2013 and considering data from the whole world. In their results, NeQuick G outperformed Klobuchar by $16 \%$. Orus Perez et al. (2018) presented some results in range and position domain using only GPS constellation for a set of stations around the world; the NeQuick $\mathrm{G}$ model presented better results in most of the time.

In this context, this paper aims to analyze the performance of both ionospheric models in multiGNSS (GPS and Galileo) single-frequency point positioning in the position domain, focusing on the Brazilian ionospheric reality. To do so, it was selected a pair of stations at different magnetic latitudes, covering all the period Galileo has been transmitting the NeQuick G ionospheric parameters from 2013 to 2018. For this purpose, the next chapter presents a brief description of the point positioning concept, and the pseudorange observation equation, and Chapter 3 describes the two ionospheric models adopted. In Chapter 4 the materials and methods used are described, and in Chapter 5 the results obtained are presented, and some discussions are made. Chapter 6 presents the conclusions. 


\section{Point Positioning}

The basic observable used in GNSS positioning is the pseudorange, obtained by the time of travel of a signal transmitted by a satellite until it reaches the receiver, and scaled by the speed of light $c$ (Odjik 2017; Seeber 2003):

$$
P_{r}^{S}=\rho_{r}^{S}(t)+T_{r}^{S}+c\left[d t_{r}(t)+d_{D C B}(t)+d_{I S B}(t)\right]-c\left[d t^{S}(t)+d^{D C B}(t)\right]+I_{r}^{S}+\varepsilon_{\mathrm{PD}}
$$

where $P_{r}^{s}$ is the pseudorange measurement, $\rho_{r}^{s}$ is the receiver-satellite range, $d t_{r}, d t^{s}$ are the receiver and satellite clock errors, respectively, $d_{D C B}, d^{D C B}$ are the receiver and satellite code hardware biases, respectively, $d_{I S B}$ is the intersystem bias (ISB), $T_{r}^{s}$ is the tropospheric delay, $I_{r}^{s}$ is the ionospheric delay, and $\varepsilon_{\mathrm{PD}}$ contains the other error sources.

With simultaneous observations of at least four satellites, and making use of the calculated satellite orbits and clocks, satellite biases, and atmospheric delays, it is possible to obtain the receiver solution composed by its tridimensional coordinates and its clock error relative to system time scale (and the ISB, when more than one system is being used).

The observation equation is non- linear for the unknowns then needing linearization (Eq. 2) (Langley et al. 2017).

$$
\Delta \rho=H \cdot \Delta x+\varepsilon
$$

where $\Delta \rho$ is the vector containing the difference between measured and calculated pseudorange observations, $H$ is the design matrix, $\varepsilon$ is the residual error vector, and $\Delta x$ is the state vector, defined for a single constellation positioning by (Eq. 3) (Langley et al. 2017):

$$
\Delta x=\left[\Delta P, \Delta\left(c d t_{r}\right)\right]
$$

where $\Delta P$ is the corrections for the estimated tridimensional station position, and $\Delta\left(c d t_{r}\right)$ is the correction for the estimated receiver clock error.

To solve the equation for the unknowns, a least squares method is used (Eq. 04) (Langley et al. 2017).

$$
\Delta x=\left(H^{T} W H\right)^{-1} H^{T} W \Delta \rho
$$

where $W$ is the weighting matrix based on the satellite elevation angle, since most of the GNSS observation errors (troposphere and ionosphere delays, multipath effect, etc.) are related to the satellite elevation angle. 


\section{Ionospheric models}

The ionosphere is the layer of the atmosphere that extends itself from about $50 \mathrm{~km}$ until more than $1000 \mathrm{~km}$ in high. It contains a partially ionized medium, as result of the $X$ and $U V$ rays of solar radiation and the incidence of charged particles. Sufficient free ions exist in the ionosphere to affect the propagation of the radio waves. When radio signals pass through the ionosphere, group delay and phase advance happen, the vertical delay going up to $32.5 \mathrm{~m}$ for L1 frequency and 53.5 m for L2 (Hobiger and Jakowski 2017; Seeber 2003).

For an accurate positioning, single-frequency users must correct as much as possible the firstorder ionospheric term, which accounts for more than $99.9 \%$ of the total ionospheric delay (Monico 2008). The ionospheric group delay, neglecting higher order terms, may be expressed as (Hobiger and Jakowski 2017):

$$
I_{r}^{S}=\frac{40.3}{f^{2}} \int_{r}^{S} N \cdot d l=\frac{40.3}{f^{2}} S T E C
$$

where $f$ is frequency $(\mathrm{Hz}), N$ is electron density (electrons $\left./ \mathrm{m}^{3}\right), S T E C$ is Slant Total Electron Content (electrons $/ \mathrm{m}^{2}$ ), representing the propagation path between receiver and satellite. This effect introduces ranging errors of several meters if not corrected. All the lonospheric Correction Algorithms (ICA), providing ionospheric delay estimation, start from the idea presented in Equation 5.

The official ICA for GPS (Klobuchar) and for Galileo (NeQuick G) single frequency positioning are described in the next sections.

\subsection{Klobuchar Model}

GPS associated ionospheric model, named Klobuchar, is based on an empirical approach (Klobuchar 1987), and is estimated to reduce about the 50\% RMS ionospheric range error worldwide (Hobiger and Jakowski 2017; Klobuchar 1987). It is defined as a single layer ionospheric model, and the ionosphere (and its TEC) is assumed to be concentrated in an infinitesimal layer, placed at an average altitude of $350 \mathrm{~km}$ from the Earth's surface. Thence, the slant delay at L1 frequency is computed from the vertical delay at the lonospheric Pierce Point (IPP) multiplying by an obliquity factor, i.e., the mapping function, for given geomagnetic location and local time (Newby and Langley 1992; Klobuchar 1987).

In the model, the diurnal variation of the ionospheric delay is simply modeled by a half-cosine function with varying amplitude and period, depending on time and geomagnetic latitude. During night time, the ionospheric delay is fixe to a constant value. The amplitude and period of the halfcosine form are centered at 14:00 local time (Hobiger and Jakowski 2017).

In order to compute the amplitude and period in any Earth location, eight coefficients of two thirddegree polynomials, are broadcasted daily in the GPS navigation messages. The GPS Ground Control Segment calculates and updates these coefficients according to season and solar activity level. 


\subsection{NeQuick G Model}

The NeQuick model is a three dimensional and time dependent semi-empirical electron density model of the ionosphere developed at the International Centre for Theoretical Physics (ICTP) Trieste, Italy, and at the University of Graz, Austria. It uses the peaks of the three main ionospheric regions (E, F1, and F2) as anchor points (EC 2016).

The electron density at any location is computed starting from the characteristic parameters such as peak electron density and peak height, and the STEC is computed by integrating TEC along the signal path. The model uses the Epstein formulation for the bottom side ionosphere and a simple formulation (semi-Epstein layer), with a thickness parameter increasing linearly with height (Radicella 2009).

The spatial and temporal behavior of key parameters is deduced from monthly tables of Comité Consultatif International des Radiocommunications (CCIR) coefficients (Hobiger and Jakowski 2017). In addition to latitudinal and longitudinal dependence of theses coefficients, a geomagnetic field dependence expressed by the modified dipole parameter modip $\mu$ was included (Radicella 2009):

$$
\tan (\mu)=\frac{1}{\sqrt{\cos \varphi}}
$$

where $I$ is the magnetic inclination at $300 \mathrm{~km}$ and $\varphi$ is the geographic latitude of the piercing point location.

An adapted version of the model, named NeQuick $G$, is used as the single frequency correction model of Galileo system. The solar activity is described by the effective ionization level Az which is computed by the Galileo operation center in order to get the best representation of the current ionization level by the model, being made available for $24 \mathrm{~h}$ on a global scale. The $A z$ is defined by (EC 2016):

$$
A z=a_{0}+a_{1} \mu+a_{2} \mu^{2}
$$

where the coefficients $a_{0}, a_{1}, a_{2}$ are optimized every $24 \mathrm{~h}$ using a set of global permanent stations and broadcasted to the users.

NeQuick $G$ is based on a more complex algorithm than Klobuchar. Implementation of NeQuick G capability on receivers also needs bit more preparation, since the model assumes availability of the CCIR maps, and dip latitudes grid file (Paakki et al. 2015; Piriz et. al 2016).

\section{Materials and Methods}

To carry out a performance comparison between Klobuchar and NeQuick G ionospheric models, the accuracy analysis of estimated coordinates obtained from a static multi-GNSS single-frequency 
point positioning is performed. The developed scientific software uses MGEX (Multi-GNSS Experiment) precise ephemeris and clocks, and the weighting matrix is based on the squared sine of the satellite elevation angle with a cutoff angle of $10^{\circ}$. GPS L1/CA and Galileo E1 pseudorange measurements are corrected for relativistic effects, satellites DCBs, and the tropospheric effect using Hopfield model and Niell mapping function (Odijk 2017; Monico 2008). The ionospheric delay is computed using Klobuchar and NeQuick $\mathrm{G}$ models, with the parameters being obtained from GPS and Galileo navigation messages, respectively. The positioning results are the estimated station tridimensional coordinates, receiver clock error relative to the GPS Time, and ISB between GPS and Galileo systems.

For the experiment, two stations (PRU2 and POAL) from CIGALA/CALIBRA (Concept for Ionospheric-Scintillation Mitigation for Professional GNSS in Latin America/ Countering GNSS high Accuracy applications Limitations due to lonospheric disturbances in BRAzil), located at different magnetic latitudes (and consequently affected by variable ionospheric activity) were selected (Table 1, Figure 1). PRU2 station is positioned at a magnetic latitude of around $-13^{\circ}$, being therefore located in the south crest region of the equatorial anomaly, where the TEC density is very high and variable, and where plasma bubbles can frequently appear, leading to the generation of irregularities such as the scintillation. POAL station, on the other hand, is located at a magnetic latitude of around $-21^{\circ}$, region characterized by weaker and more regular TEC activity. The selection of these two stations captures the ionospheric activity extremes in the Brazilian region.

Table 1: Stations approximate coordinates

\begin{tabular}{c|c|c|c|c|c}
\hline Station & Location & $\begin{array}{c}\text { Geographic } \\
\text { Latitude }\left({ }^{\circ}\right)\end{array}$ & $\begin{array}{c}\text { Geographic } \\
\text { Longitude }\left({ }^{\circ}\right)\end{array}$ & Height $(\mathrm{m})$ & $\begin{array}{c}\text { Magnetic } \\
\text { Latitude }\left({ }^{\circ}\right)\end{array}$ \\
\hline PRU2 & Presidente Prudente (SP) & -22.1220 & -51.4071 & 441.7 & -13.09 \\
\hline POAL & Porto Alegre (RS) & -30.0739 & -51.1197 & 77.2 & -21.01 \\
\hline
\end{tabular}

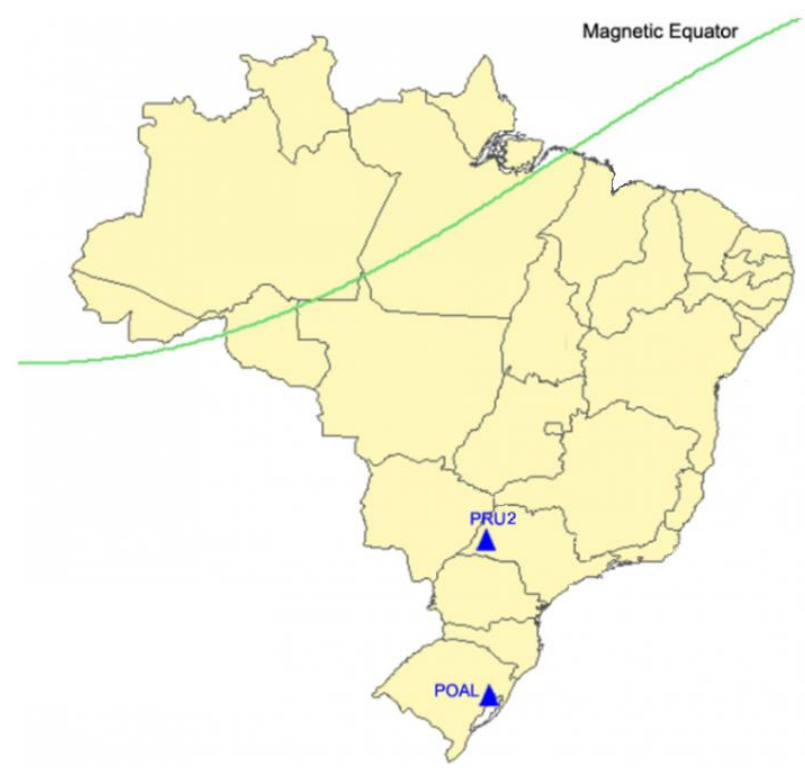

Figure 1: Selected stations.

Source: Adapted from https://www.gsa.europa.eu/news/fp7-success-story-calibra-demosvalidate-tangible-results. 
To analyze the performance of both models under the effects of different ionospheric conditions, it was selected three days of June and three days of October from 2013 (year that Galileo started broadcasting the NeQuick $G$ parameters) to 2018 (from the $20^{\text {th }}$ to the $22^{\text {nd }}$ of June and October, except for October 2018, when the selected days were the $30^{\text {th }}$ and the $31^{\text {st }}$ due to data availability). The selected days of June were close to the Winter Solstice in the Southern Hemisphere, characterized by weak ionospheric activity, and the days of October were close to the Spring Equinox in the Southern Hemisphere, characterized by strong ionospheric activity. The selected period from 2013 to 2018 covers part of the solar cycle 24 (and its possible transition to solar cycle 25), which reached its peak in 2014 and is getting weaker since then (Figure 2).

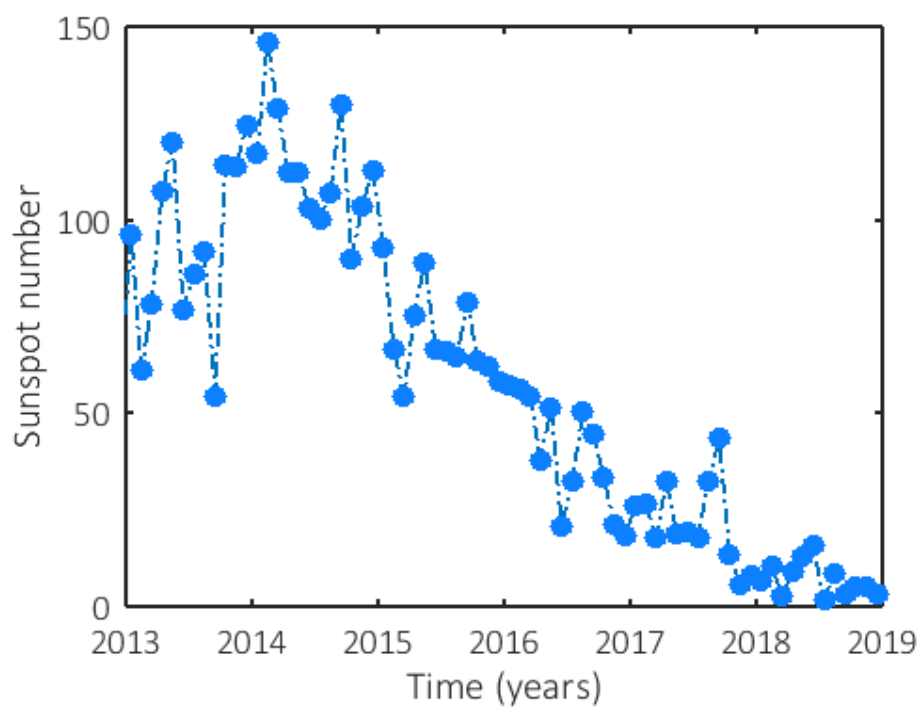

Figure 2: Sunspot number for the selected period.

Source: Adapted from http://www.sidc.be/silso/

The performance comparison between the two models have been conducted at the position domain. To evaluate the efficacy of the ionospheric models, the estimated position without ionospheric correction (called "no-iono") is also analyzed. The analysis is presented mainly in terms of the tridimensional position root mean square error (RMSE), using as reference the stations known coordinates.

\section{Results and Discussions}

Figure 3 presents the estimated position tridimensional RMSE for both PRU2 and POAL stations, considering the results of the three processed days of June and of October and the three ionospheric approaches: no-iono, Klobuchar and NeQuick G. Analyzing this figure, it is possible to note the seasonal behavior of the ionosphere: the errors are always larger in October than in June of each year, since it is a month of more active ionosphere. The largest errors are always associated with PRU2 station when compared to the same periods of POAL due to its location with respect to the magnetic equator. The largest errors, when no ionospheric correction is applied, are found 
in the results of October 2014, peak of the solar cycle, with an RMSE of $18.0 \mathrm{~m}$ for PRU2 and of $16.9 \mathrm{~m}$ for POAL. The smallest errors (for no-iono processing), on the other hand, are associated to the results of June 2018, month of weak ionospheric activity, and when the solar cycle is reaching its lowest activity (RMSE of $3.4 \mathrm{~m}$ for PRU2 and of $2.9 \mathrm{~m}$ for POAL).

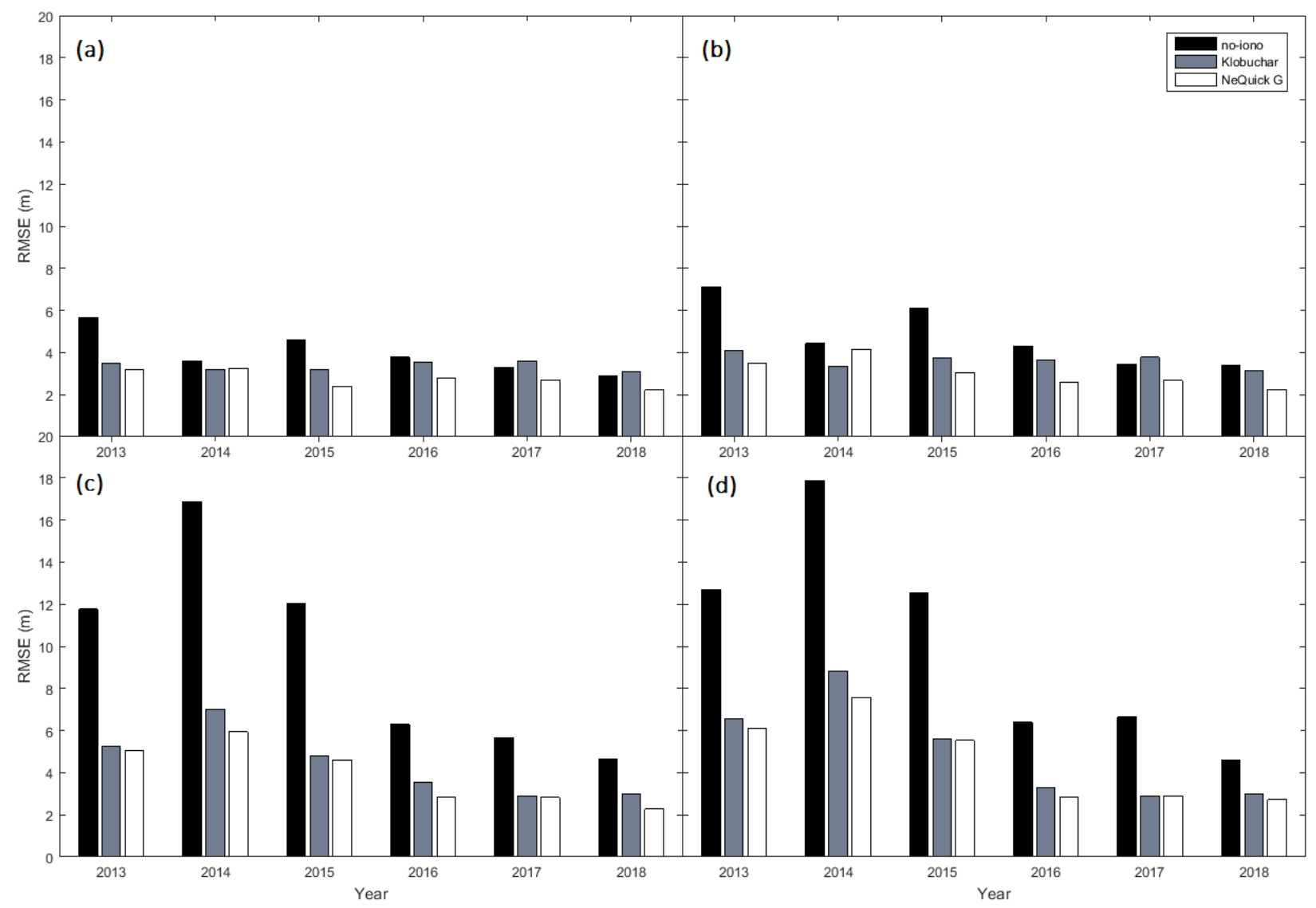

Figure 3: Estimated position 3D RMSE for June, stations (a) POAL and (b) PRU2, and for October, stations (c) POAL and (d) PRU2.

Comparing the performance of the ionospheric models, it is possible to note that, in almost all the cases, the usage of a model to reduce the ionospheric delay is beneficial to the position estimate, especially when the ionosphere is active (month of October, years close to the solar cycle peak). Considering all the periods and stations, the largest improvement in positioning error is of $65 \%$, for POAL station, October 2014, when the tridimensional RMS drops from $16.9 \mathrm{~m}$ when no ionospheric model is applied to $6.0 \mathrm{~m}$ with NeQuick G model. Comparing one model to another, NeQuick $G$ model performs better than Klobuchar in $92 \%$ of the time. The largest improvement is found in periods of weak ionospheric activity: POAL station, June 2018, and PRU2 station, June 2016, 2017 and 2018, when the positioning error was improved by $29 \%$.

To better understand the results presented in Figure 3, Figures 4 and 5 present an epoch-to-epoch plot of the horizontal and vertical errors (without ionospheric correction) of the estimated position of PRU2, 22 October 2014 (Figure 4, largest RMSE in Figure 3), and of 21 June 2018 (Figure 5, second smallest RMSE in Figure 3, chosen to keep the analysis focused on PRU2 station), associated with an epoch-to-epoch plot of the STEC (in TECUnits, 1 TECU $=10^{16} \mathrm{el} / \mathrm{m}^{2}$, equivalent to a range error of $16.2 \mathrm{~cm}$ at L1 frequency) and S4 index, obtained from the lonospheric Scintillation Monitor Receivers (ISMR) used in the experiment. It is important to mention that, 
although the analysis is exemplified through these two days and plots, it can be extended to the other periods and stations.

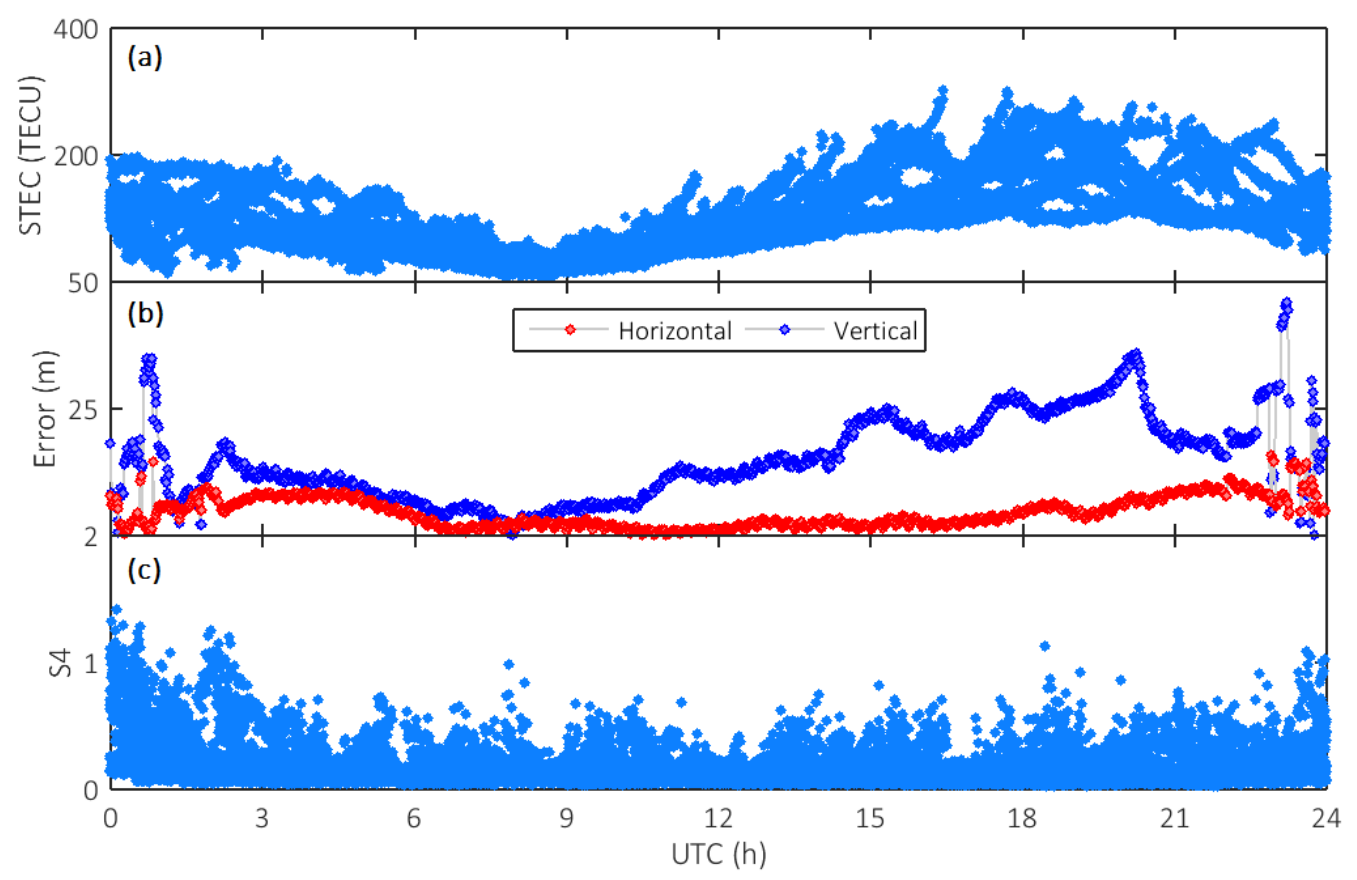

Figure 4: (a) STEC, (b) horizontal and vertical position error (no-iono) and (c) S4 for PRU2 station, 22 October 2014.

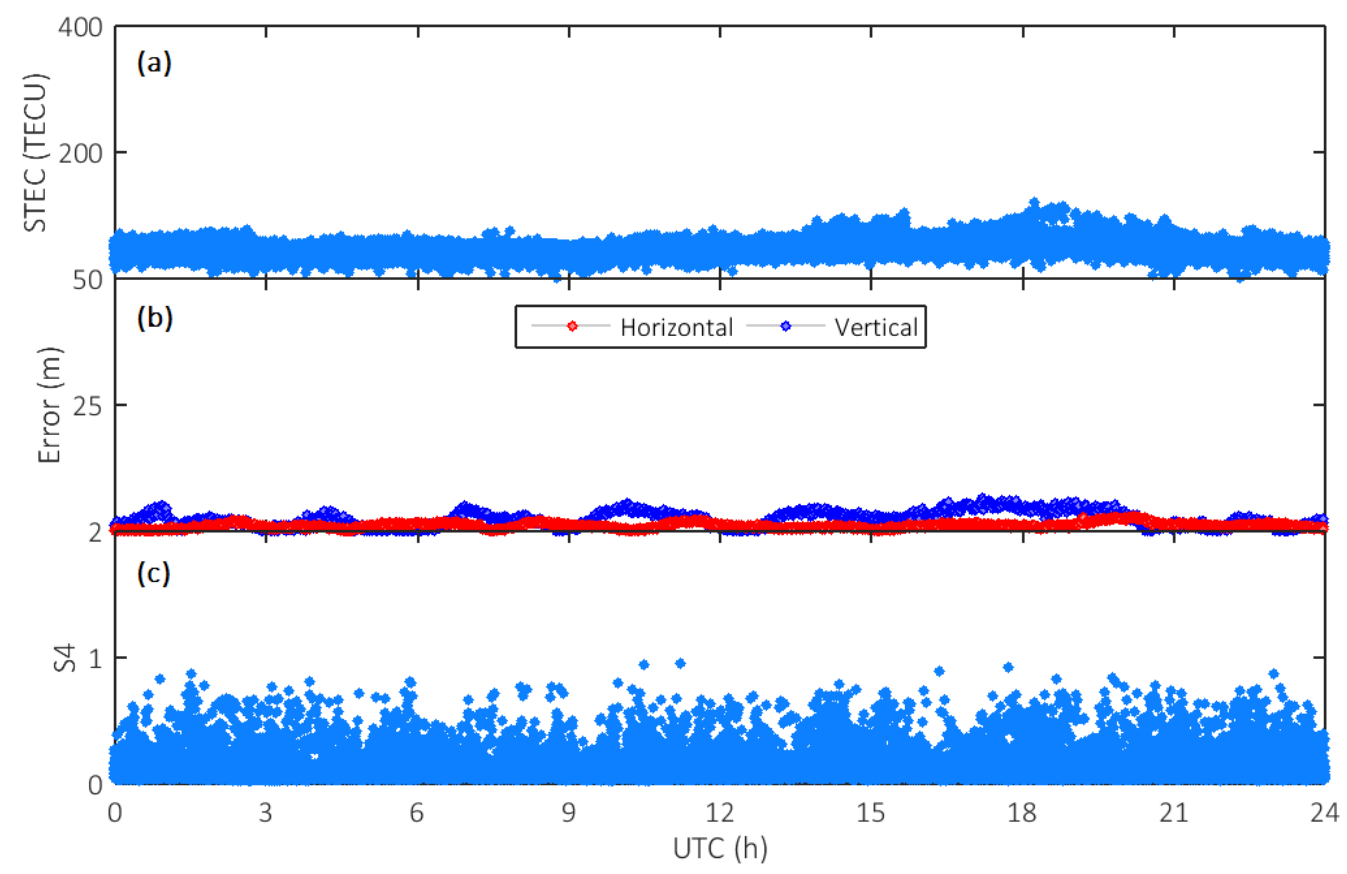

Figure 5: (a) STEC, (b) horizontal and vertical error (no-iono) and (c) S4 for PRU2 station, 21 June 2018.

In Figures 4 and 5 (a), it is possible to note the behavior of the ionosphere throughout the day: the smallest values of electron density are found during the nighttime, then reaching a peak during the afternoon, local time (UTC -3). Considering the months of October 2014 and June 2018 in 
relation to the time of year and solar cycle, it was already expected the TEC to be much higher in Figure 4 (maximum of around 300 TECU) than in Figure 5 (maximum of around 100 TECU).

Analyzing Figures 4 and 5 (b), one can note the influence of the TEC in the position estimate, especially in the vertical component (which is also influenced by the satellite geometry): in the day of October 2014, the average vertical error is of $15.0 \mathrm{~m}$, while in June 2018 it goes down to $2.4 \mathrm{~m}$. The horizontal error is less affected by the ionosphere, going from an average error of $4.5 \mathrm{~m}$ in October 2014 to $1.1 \mathrm{~m}$ in June 2018. Although one can see the correlation of the TEC with the position error (in the vertical component, October 2014, for example, it is possible to note a peak of $35.9 \mathrm{~m}$ in the error at around $20 \mathrm{~h} 15 \mathrm{~min}$ UTC, $17 \mathrm{~h} 15 \mathrm{~min}$ local time, which agrees with the TEC maximum), the TEC is not capable of explaining some peaks in the error that occur during nighttime, in both horizontal (maximum of $15.8 \mathrm{~m}$ ) and vertical (maximum of $45.9 \mathrm{~m}$ ) components. These peaks can be explained by the equatorial anomaly, which reaches a second daily maximum development during nighttime in periods of solar maximum (Skone et al. 2001), and by the ionospheric scintillation.

Figures 4 and 5 (c) present the S4 index for the two analyzed days. The S4 is an index computed from the satellite signal power or signal intensity (Van Dierendonck 2001), and is used to characterize the ionospheric scintillations, rapid variations in the amplitude and phase of the GNSS signal caused by small scale irregularities in the ionosphere, degrading the position estimate. Ionospheric scintillation severity is usually classified as strong when the S4 index is higher than 1 (Tiwari et al., 2011). As can be noted in Figure 4 (c) and is documented in literature (Kelley, 1989; Marques et al., 2018), scintillations generally occur in periods of active ionosphere starting after local sunset, approximately $18 \mathrm{~h}$ local time, affecting the GNSS signals until around $3 \mathrm{~h}$ local time in the morning. By comparing Figure 4 (b) and (c), it is clearly noticeable that the error peaks occur simultaneously to periods of strong ionospheric scintillation.

Figures 6 and 7 present the epoch-to-epoch plot of the horizontal and vertical errors of the same two days previously characterized, but now presenting how the time series behave when the Klobuchar and NeQuick $\mathrm{G}$ models are applied. Please note that the scale for the two graphs is not the same, to better visualize and understand the results. 


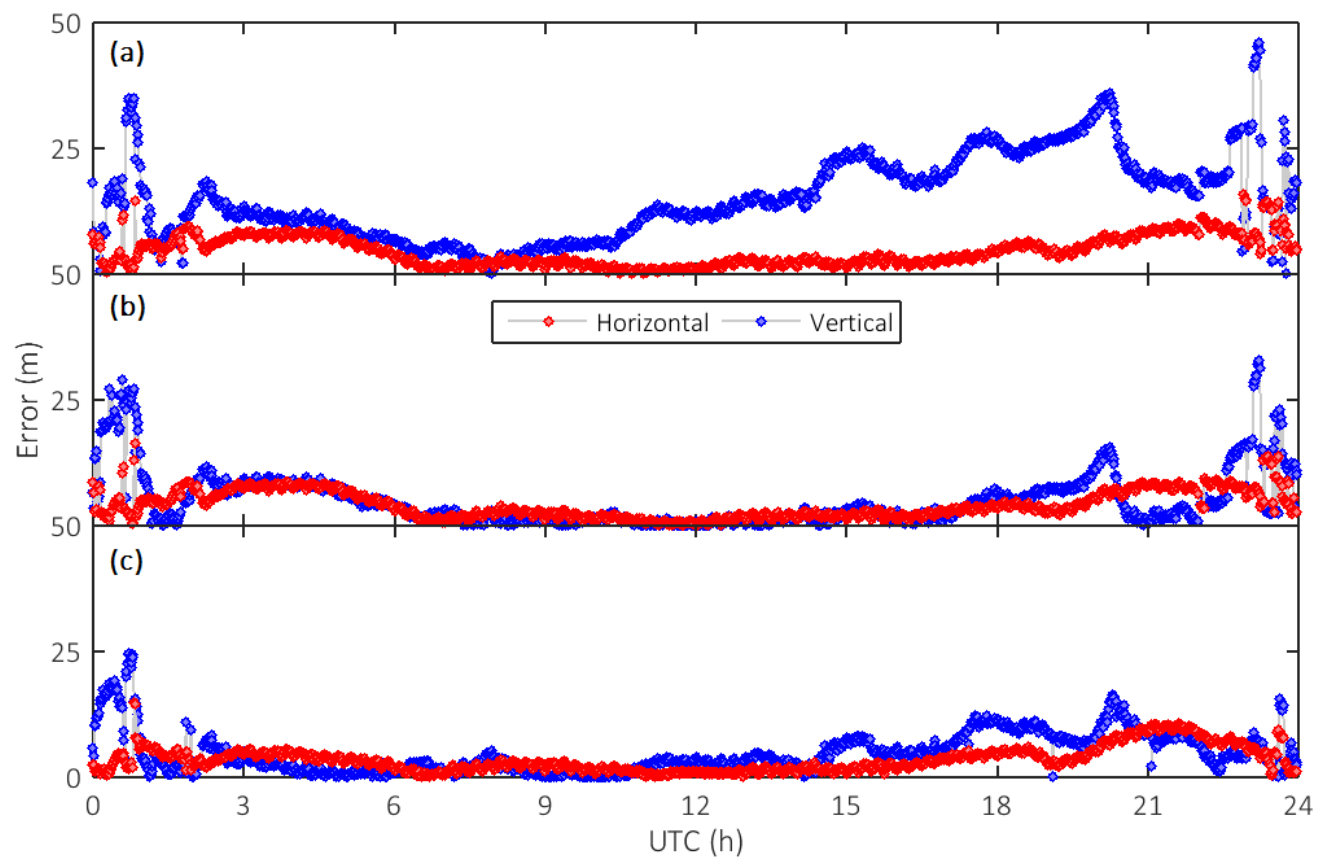

Figure 6: Horizontal and vertical error for PRU2 station, 22 October 2014 for processing (a) without ionospheric correction, and with (b) Klobuchar and (c) NeQuick G models.

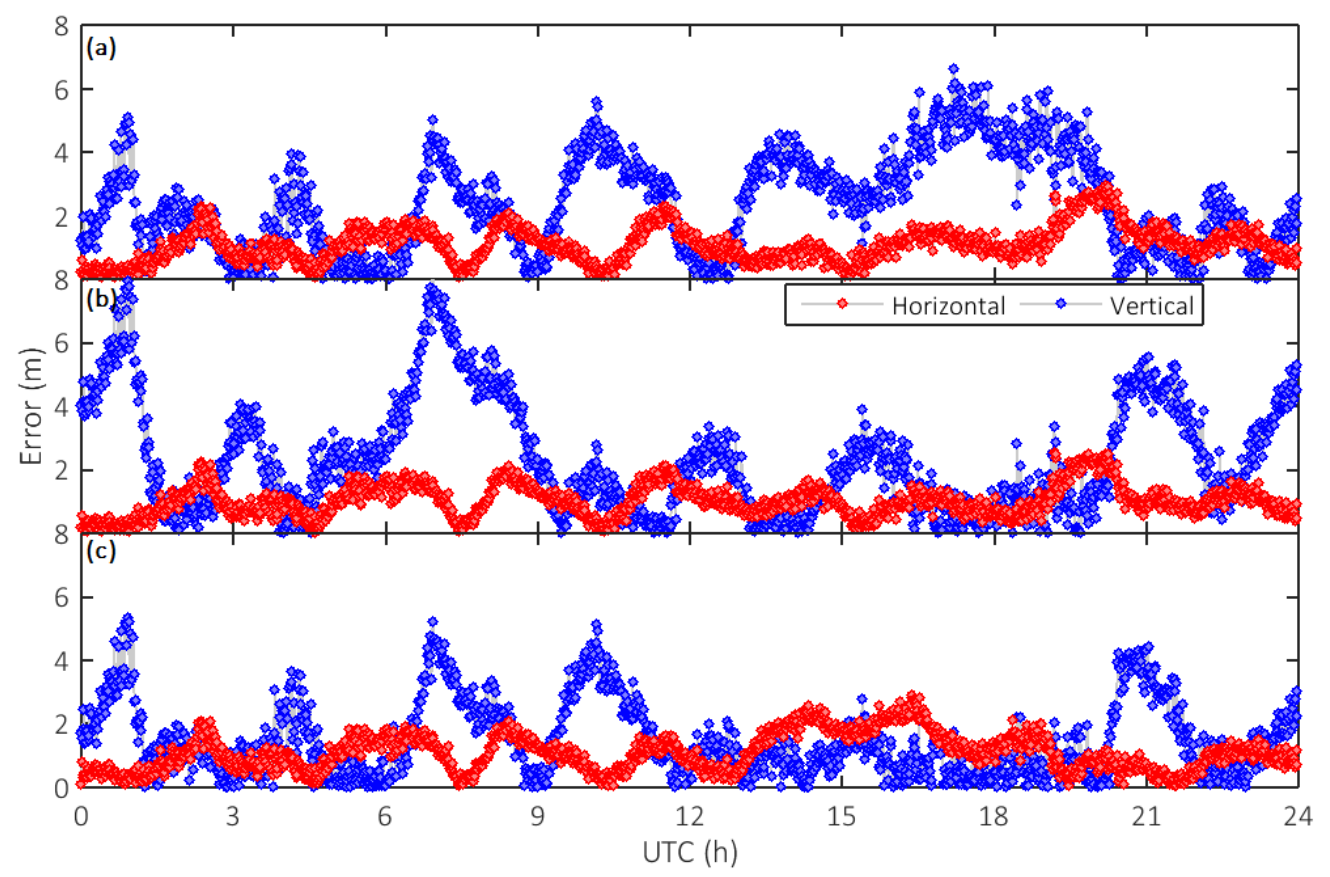

Figure 7: Horizontal and vertical error for PRU2 station, 21 June 2018 for processing (a) without ionospheric correction, and with (b) Klobuchar and (c) NeQuick models.

Analyzing Figures 6 and 7, different conclusions can be taken from the horizontal and vertical components. In the horizontal one, practically no difference can be noticed between the models and the no-iono solution in the period of quiet ionosphere (Figure 7) (horizontal mean error of 1.1 $\mathrm{m}$ for the three processing strategies). In the period of active ionosphere (Figure 6 ), the horizontal 
mean error goes from $4.5 \mathrm{~m}$ when no ionospheric correction is applied, to $4.1 \mathrm{~m}$ with Klobuchar (improvement of 9\%) and $3.5 \mathrm{~m}$ with NeQuick G (improvement of 22\%).

In the up component (the one most affected by the ionospheric delay), the impact of the ionospheric correction is higher. For the period of weak ionospheric activity, the vertical mean error goes from $2.4 \mathrm{~m}$ no-iono to $2.3 \mathrm{~m}$ with Klobuchar (improvement of $4 \%$ ) and to $1.5 \mathrm{~m}$ with NeQuick G (improvement of 38\%). In Figure 7, however, it is possible to note that, at some epochs, the usage of an ionospheric model may degrade the position estimate. This happens especially with the vertical component with Klobuchar model during nighttime, when the ionospheric delay is set to a constant of $5 \mathrm{~ns}$; the model performs better during daytime, when it is modeled by a half-cosine function. The most significant improvements occur in the vertical component during the active ionosphere period (Figure 6): the vertical mean error goes from $15.0 \mathrm{~m}$ no-iono to 4.9 $\mathrm{m}$ with Klobuchar (improvement of 67\%) and to $4.7 \mathrm{~m}$ (improvement of 69\%) with NeQuick G.

Regarding the errors caused by the equatorial anomaly and by the ionospheric scintillation (Figure $6)$, it is possible to note the deficiency of both models in dealing with it. Although the error is expressively reduced when either model is used (in the vertical component, the maximum error is reduced from $45.9 \mathrm{~m}$ no-iono to $32.8 \mathrm{~m}$ with Klobuchar and to $24.7 \mathrm{~m}$ with NeQuick $\mathrm{G}$ ), the errors are still far larger than what is expected to the nighttime in the absence of scintillation. This noted deficiency in ionospheric models agrees with what was observed in Matsuoka and Camargo (2007) and in Armendaris et al. (2009).

It is worth mentioning that some factors other than the solar cycle period may be affecting the results accuracy (better results in recent years), e.g. the quality with which satellite orbits and DCBs are estimated, the number of stations used to compute the set of ionospheric parameters broadcasted by the GPS and Galileo satellites, and, in a more substantial way, the number of Galileo satellites used in the experiment (in 2013, 2014 and 2015, the number of tracked Galileo satellites varied from 0 to 3, with an average of 1 satellite; in 2017 and 2018, this number went to 5 satellites, with a minimum of 2 and maximum of 7); the higher the number of tracked satellites, the better the constellation geometry and, consequently, the better the position estimate. However, these factors affect all the processing strategies (no ionospheric correction, and Klobuchar and NeQuick $\mathrm{G}$ models) in an equal way, therefore not affecting or compromising the results and conclusions presented in this work.

To summarize the results described and discussed in this section, Figure 8 presents the improvements in the estimated tridimensional position of each model with respect to the no ionospheric solution, and the improvement of the NeQuick $\mathrm{G}$ model with respect to the Klobuchar model, averaged from both stations and all the years processed for the months of June and October. 


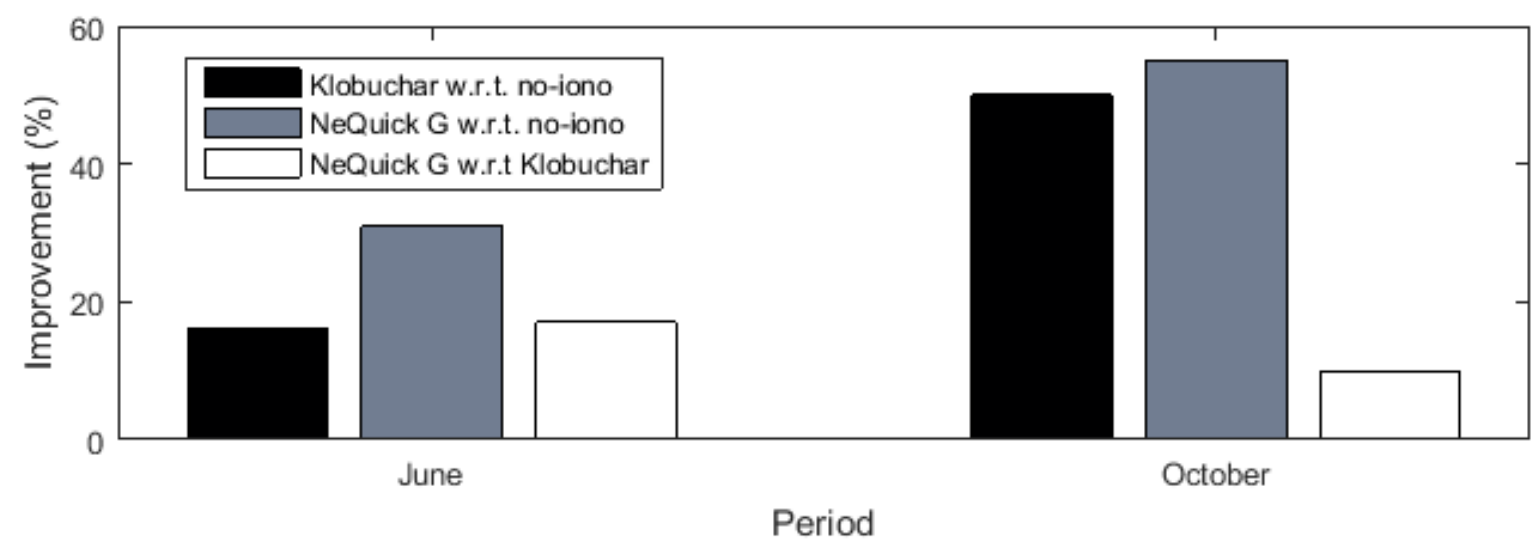

Figure 8: Tridimensional position estimate improvement for all the stations and periods analyzed, averaged for the months of June and October.

Considering the averaged results presented in Figure 8, it is possible to conclude that both models are capable of accounting for part of the delay caused by the ionosphere in GNSS observations, especially in periods of strong ionospheric activity (Klobuchar improves the position estimate by $50 \%$ in October, and NeQuick $\mathrm{G}$ by $55 \%$ ). In periods of weak ionospheric activity, the improvement has a lower impact (16\% for Klobuchar and 31\% for NeQuick G in June). However, it is notable that NeQuick $G$ model outperforms Klobuchar model in both cases, especially in periods of weak ionospheric activity (17\% better in June, and 10\% better in October).

\section{Conclusions}

In this study the point positioning performance of a multi-GNSS (GPS and Galileo) single frequency (L1/CA for GPS, and E1 for Galileo) receiver using two broadcast ionospheric models, Klobuchar, associated to the GPS, and NeQuick G, associated to Galileo, and without ionospheric corrections are analyzed. For the experiments, two Brazilian stations located in different parts of the country were selected, and the analyzed period covered a time gap of 6 years, picking up days from 2013 to 2018 (covering all the time NeQuick G parameters have been transmitted by Galileo satellites), therefore considering seasonal and long period variations that affect the ionosphere.

From the results obtained, it emerges that there is a benefit in positioning if an ionospheric model is used, primarily for the vertical component, which is the most affected by the ionospheric delay. The usage of both models improves the positioning accuracy, especially in periods of strong ionospheric activity, when the errors are larger. Considering all periods and stations analyzed, NeQuick G model overcomes Klobuchar's in almost all the cases; this improvement is most noticeable in periods of weak ionospheric activity, when NeQuick $G$ is up to $29 \%$ better than Klobuchar.

However, it is important to mention the difference in complexity of both models: while Klobuchar is a very simple one, and the ionosphere is modeled by a half-cosine function, NeQuick G involves a large set of functions used to model the tridimensional electron density present in the ionosphere main layers. This complexity results in the need for longer execution time (NeQuick $G$ execution time is around 60 times longer than Klobuchar's), and its implementation in a real time 
low-cost single-frequency receiver may not be straightforward, and maybe not worthy when considering the accuracy required in the activities that generally involve this kind of receiver.

Therefore, it is possible to conclude that, for the Brazilian region, NeQuick $G$ better models the ionosphere than Klobuchar in most of the time, for both PRU2 and POAL stations (the former located close to the magnetic equator, and the latter further from it), and for the period of 2013 to 2018. NeQuick $G$ is especially recommended when better positioning accuracy is required, and in post-processed activities, when its execution time may not be a problem.

\section{ACKNOWLEDGEMENT}

The authors would like to thank FAPESP (Foundation for Research Support of São Paulo), CAPES (Coordination for the Improvement of Higher Education Personnel) and CNPq (National Council of Research and Developing) for the financial support provided to this research (FAPESP research project - process numbers 2016/24861-3 and 2017-22223-2; CNPq research project - process number 303553/2017-0).

Thanks to the CIGALA/CALIBRA project, both funded by the European Commission (EC) in the framework of the FP7-GALILEO-2009-GSA and FP7-GALILEO-2011-GSA-1a, respectively, and FAPESP Project Number 06/04008-2.

\section{AUTHOR'S CONTRIBUTION}

Definition of research problem (P.T.S.J., D.B.M.A. and C.M.S.), Literature review (P.T.S.J.), Definition of methodological procedures (P.T.S.J., D.B.M.A. and C.M.S.), Data collection (P.T.S.J.), Data processing (P.T.S.J.), Analysis and interpretation of data (P.T.S.J., D.B.M.A. and C.M.S.), Manuscript writing (P.T.S.J., D.B.M.A. and C.M.S.).

\section{REFERENCES}

Angrisano, A.; Gaglione, S.; Gioia, C.; Massaro, M.; Troisi, S. 2013. Benefit of the NeQuick Galileo version in GNSS single-point positioning. International Journal of Navigation and Observation.

Armendaris, O. C.; Matsuoka, M. T.; Camargo, P. O. 2009. Desempenho do modelo global da ionosfera do IGS: avaliação no posicionamento por ponto na região sul do Brasil em período de alta atividade solar. Boletim de Ciências Geodésicas, v. 15, n. 2, p. 208-223.

EUROPEAN COMMISSION (EC). European GNSS (Galileo) open service ionospheric correction algorithm for Galileo single frequency users. 2016. Available at: < https://www.gsceuropa.eu/system/files/galileo_documents/Galileo_lonospheric_Model.pdf> [Acessed 25 Apr. 2018].

GSA - EUROPEAN GNSS AGENCY. 2016. Constellation information. Available at: < https://www.gsceuropa.eu/system-status/Constellation-Information> [Acessed 30 Apr. 2018]. 
GSA - EUROPEAN GNSS AGENCY. 2018. Galileo services. Available at: <https://www.gsa.europa.eu/galileo/services> [Acessed 29 Mar. 2018].

GPS.GOV. Space segment. 2018. Available at: <http://www.gps.gov/systems/gps/space/\#generations/>. [Acessed 30 Apr. 2018].

Hobiger, T.; Jakowski, N. 2017. Atmospheric Signal Propagation. In: Teunissen, P. J. G. Montenbruck, O., eds. Springer Handbook of Global Navigation Satellite Systems. Springer, Berlin. Hofmann-Wellenhof, B.; Lichtenegger, H.; Wasle, E. 2008. GNSS - Global navigation satellite systems, GPS, GLONASS, Galileo and more. Spring-Verlage Wien.

Klobuchar, J. A. 1987. Ionospheric time-delay algorithm for single-frequency GPS users. IEEE Transactions on Aerospace and Electronic Systems, v.AES-23, n.3, p.325-331.

Langley, R. B.; Teunissen, P. J. G.; Montenbruck, O. 2017. Introduction to GNSS. In: Teunissen, P. J. G.; Montenbruck, O., eds Springer Handbook of Global Navigation Satellite Systems. Springer, Berlin.

Marques, H. A.; Marques, H. A. S.; Aquino, M.; Veettil, S. V.; Monico, J. F. G. 2018. Accuracy assessment of Precise Point Positioning with multi-constellation GNSS data under ionospheric scintillation effects. Journal of Space Weather and Space Climate, 8, p.A15.

Matsuoka, M. T.; Camargo, P. O. 2007. Correção ionosférica utilizando os mapas globais do TEC do IGS: avaliação no posicionamento por ponto na região brasileira. Boletim de Ciências Geodésicas, v. 13, n. 2, p. 253-270.

Monico, J. F. G. 2008. Posicionamento pelo GNSS: descrição, fundamentos e aplicações. 2nd ed. São Paulo: UNESP.

Newby, S. P.; Langley, R. B. 1992. Three Alternative Empirical lonospheric Models - Are They Better Than the GPS Broadcast Model? In: Sixth International Geodetic Symposium on Satellite Positioning. Proceedings... v.1,p.240-4.

Odijk, D. 2017. Positioning Model. In: Teunissen, P. J. G.; Montenbruck, O., eds. Springer Handbook of Global Navigation Satellite Systems. Springer, Berlin.

Orus Perez, R.; Parro-Jimenez, J. M.; Prieto-Cerdeira, R. 2018. Status of NeQuick G after the solar maximum of cycle 24. Radio Science, 53(3), pp.257-268.

Paakki, T.; Della Rosa, F.; Nurmi, J. 2015. PVT Computation Issues in Mixed Galileo/GPS Reception. In: Nurmi, J. Lohan, E. S. Sand, S. Hurkskainen, H., eds. GALILEO Positioning Technology. New York: Springer.

Piriz, R.; Roldan, P.; Golcz, R.; Moriana, C.; Leute, J. 2016. Performance of the NeQuick G iono model for single-frequency GNSS timing applications. European Frequency and Time Forum (EFTF). IEEE.

Radicella, S. M. 2009. The NeQuick Model Genesis, Uses and Evolution. In: Annals of Geophysics, vol. 52, n. 3/4, p. 417-422, jun./aug.

Seeber, G. 2003. Satellite Geodesy: Foundations, Methods, and Applications. Berlin, New York: Walter de Gruyter.

Skone, S.; Knudsen, K.; De Jong, M. 2001. Limitations in GPS receiver tracking performance under ionospheric scintillation conditions. Physics and Chemistry of the Earth (A), v. 26, n. 6-8, p. 613621. 
Tiwari, R. Skone, S. Tiwari, S. Strangeways, H.J. 2011. WBMod assisted PLL GPS software receiver for mitigating scintillation affect in high latitude region. XXXth URSI General Assembly and Scientific Symposium. IEEE.

Van Dierendonck, A. J. 2001. Measuring ionospheric scintillation effects from GPS signals. In: ION 59th Annual Meeting. Albuquerque, New Mexico, pp. 391-396

Vani, B. C.; Shimabukuro, M. H.; Monico, J. F. G. 2017. Visual exploration and analysis of ionospheric scintillation monitoring data: The ISMR Query Tool. Computers \& Geosciences.

Wang, N.; Yuan, Y.; Li, Z.; Li, Y.; Huo, X.; Li, M. 2017. An examination of the Galileo NeQuick model: comparison with GPS and JASON TEC. GPS solutions, 21(2), pp.605-615. 